1934

\title{
Cavernous sinus thrombophlebitis
}

Arthur A. Enos

University of Nebraska Medical Center

This manuscript is historical in nature and may not reflect current medical research and practice. Search PubMed for current research.

Follow this and additional works at: https://digitalcommons.unmc.edu/mdtheses

Part of the Medical Education Commons

\section{Recommended Citation}

Enos, Arthur A., "Cavernous sinus thrombophlebitis" (1934). MD Theses. 617.

https://digitalcommons.unmc.edu/mdtheses/617

This Thesis is brought to you for free and open access by the Special Collections at DigitalCommons@UNMC. It has been accepted for inclusion in MD Theses by an authorized administrator of DigitalCommons@UNMC. For more information, please contact digitalcommons@unmc.edu. 
CAVERNOUS SINUS THROHBOPHLEBITIS

complicating

FACIAL INFECTIONS

by

ARTHUR A. ENOS 


\section{CONTENTS}

Chapter

Page

I Introduction

A. Definition 3

B. Historical 4

C. Frequency of Cases 5

D. Objective of this Thesis 8

II Anatomy of the Cavernous Sinus and
its Communications

II Etiology of Cavernous Sinus Thrombophlebitis 16

IV symptomatology 20

$\checkmark$ Laboratory findings

A. Blood findings 24

B. Spinal Fluid Examination 24

C. Bacteriology 25

VI Diagnosis 26

A. Differential Diagnosis 27

VII Progress

VIII Prevention

A. Potential dangers and the metrods of treatment of facial infections. 31

B. Angular Vein Ligation 40

IX Prognosis 43 
Contents--Ooncluded

Chapter

Page

$X$ Treatment

45

A. Surgical Treatment 45

B. Internal Carotid Ligation 52

C. Internal Jugular Ligation 54

D. Medical Treatment 56

XI Conclusion $\quad 58$ 


\section{CAVERNOUS SINUS THROMBOPHLEBITIS}

\section{COUPLICATING FACIAL INFEOTIONS}

I--Introduction

Thrombosis of the cavernous sinus is the rarest of large sinus thromboses, and, according to a careful study made by Dorland Smith (55), (67), less than three hundred cases have been published since its recognition by Herman Knapp in 1868. Because it occurs so seldom in the practice of any one man, it is very easy for the early deoisive recognition to fall.

The study of cavernous sinus thrombosis has been limited in the past, according to Langworthy (34), first, because of the rarety of cases; he believes that the average doctor sees only two or three cases in a lifetime, and second, because so few men consider the sinus avallable for surgical interference.

Although acute infectious cases of cavernous sinus thromboses are relatively rare if one considers the number of cases already reported in the literature, yet it is believed by many that this disease occurs more frequently than reports indicate, and that many cases occur which elther are not reported or are not recognized as such. (56)

Up unt1l 1924 about 588 cases had been reported and many have been added since this time.

It seems that this disease presents such a striking appearance, and its relation to adjacent foci is so constant 
that one wonders why it goes undiagnosed. Lack of recognition of this lesion may be explained by two factors (15), first, because of the unusual structure and the obscure position of the cavernous sinus, and second, the early and fatal meningitis existing as a complication.

Dixon (15) rather humorously states that nature must have been aware of her mistake when she constructed the cavernous sinus, because man has been so long in attacking this sinus surgically, and has never had much success in such an operation up to the present time.

The presence of a thrombus in a venous sinus is the attempt on the part of nature to wall off and to destroy an infection which has penetrated or is penetrating the sinus walls. It is now generally believed that these efforts at spontaneous obliteration of the sinus are at time successful. Dr. Ewing W. Day (13) has reported cases of cavernous sinus thrombosis, unsuspected by the physician at the time, resulting in spontaneous cure. These cases are practically without symptoms. At the other extreme there are the rapidly fulminating cases with violent septic symptoms, which symptoms too often are considered necessary for a diagnosis. Between these two extremes there are many variations. Symptoms present in sinus thrombosis are indicative of the breaking down of nature's barriers, and a bacteremia results. The thrombus does not kill, but it is rather the blood stream infection resulting from its disintegration. 
A. Definition

It is important to distinguish between a thrombosis of the cavernous sinus and thrombophlebitis. The addition of the phlebitis to the thrombosis makes a tremendous difference. The formation of a thrombus th any vein is a protective reaction and should cause no symptoms or complications if the collateral circulation is adequate and if this thrombus does not become infective. A sterile thrombus of the cavernous sinus may therefore cause no symptoms if it is confined to tris sinus alone. An infected thrombus (thrombophlebitis) of this sinus, however, gives marked and rapidly advancing symptoms. The tinrombosis spreads rapidy to the communicating veins in its attempt to prevent the infection from entering the circulation. There is soon the involvement of the ophthalmic veins, causing the characteristic eye symptoms. (10)

There are three separate and distinct types of the disease. The marasmic form is never primary, according to Macrwen, but occurs in connection with the same condition of the longitudinal or lateral sinus. Systemic debility is a predisposing factor. The traumatic form results from injury, such as may occur in operations upon the Gasserian ganglion, in the pituitary region, or upon the sphenoid sinus. (22). Wounds of the orbit due to penetration by a foreign body and various types of fractures of the skull may also be 
causative factors (39). The infective form is the most common. The infection may take place by direct extension from neighboring intracranial foci, as brain abscess, meningitis, sphenoiditis, or caries of the petrous portion of the temporal bone, or it may be blood-borne through the venous channels, which communicate with the sinus directly or indirectly (23).

The cavernous sinuses are so named because they present the picture of a reticulated structure traversed by numerous interlacing filaments which divide the sinus cavity into irregular compartments (44). A definition of the word sinus is "a dilated channel for venous blood found chiefly within the craniura." (36)

B. Historical.

Pulsating exophthalmus was first described in 1809 by Benjamin Travers. He not only first described it, but was also the first to describe its surgical treatment and ligate the cominon carotid for relief. This was a very remarkable proccedure at that time, aince it antedated the use of anaesthetics (1). Abercrombie in 1818 gave the first knowledge of cavernous sinus thrombosis. He described such cases from autopsy findings in his book published in 1818. Duncan likewise observed it in 1821 at a postmortem. (39) (7) (54). clinically, Vigla was probably the first to record it in 1839. He was followed by Castleman and Ducrest in 1846 . 
Other early reports were made by von pitha in 1859, and von Cohn in 1860. (18) Knapp in 1868 treats the subject very much as it is treated today along the line of differential diagnosis, differentiating between cavernous sinus thrombosis, orbital abscess, and other inflammatory conditions that cause exophthalmos (18). In this study he mentioned Brandt, Dreyfuss, Gerber, Hajek, and St. Clair Thomson. Dwight and Germain in 1902, and Barthex in the same year were the first to attack the sinus surgically, but the patients succumbed. (39), (7), (54).

H. G. Langworthy is another man who has made important contributions toward the subject, and he reviewed it in the American Encyclopedia of Ophthalmology in 1913. (92)

Probably W. P. Eagleton is the outstanding recent contributor on the subject, and his book was published in 1926.

\section{Frequency of Cases}

In reviewing the literature, Dr. Francis S. Mainzer found approximately 350 cases were reported. Chrisholm and Tatkins found 8 cases in 50,000 surgical cases on the surgical service at John Hopkins Hospital, which averages one case in 6,250. (39), (11), (54).

The New York hospitals reported 21 cases in 80,000 admisstons, while the clearfield hospital reported 2 cases in 50,000 admissions. From the se statistics we may at once see the rarety. Probably it occurs as often in foreign 
countries as we see it here in this country. Foreign literature reported 19 cases, while there were reported 21 cases in this country between 1917 and 1930. Of these cases of the last series two are reported to have recovered. From this we may have some idea of the high mortality rate. (39).

In the ear, nose and throat department of the Royal Infirmary at Edinburgh, between 1908 and 1925, Turnes and Reynolds found 12 cases in 56,880 patients, an average of one in 4,740. There is no doubt that when necropsy is not performed many cases are overlooked because of the lack of classical eye symptoms, the patient dying of a meningitis. This fact is brought out by Weizenhoffer (61).

Out of 182 cases reported up unt11 1902, Germaln (17) listed the sources of infections as follows: from the eye 4, nose 9 , mouth 14, face 34, and 11ps 2. Up unt11 1931 about 350 cases had been recorded, according to Brown, and In a serles of 140 cases collected by Dorland Smith (1918), 35 per cent were due to infection of the face or orbit with a spread to the cavernous sinus through the ophthalmic veins. A further 40 per cent were due to ear infections, 13 per cent to infections of the mouth and throat, 9 per cent to the nose, and 32 per cent to other causes. (7), (54).

In a study made by Turner and Reynolds, the pathways of infection present were as follows: In 13 cases the infection reached the sinus by way of venous channels of the 
face, pharynx, air cavities, and the cleft of the middle ear; In 8 cases the preliminary stage of the infective process was by direct extension through the bone. In the remaining cases the infection spread to the blood sinus from the sphenoldal air sinus entirely by direct extension of the inflammation through the bone and dura mater.(47) (58) According to Feizenhoffer (61), infections of the middle ear, face, and orbit are the origin of 75 per cent of cases of cavernous sinus thrombosis.

Dixon (15) states that the most frequent foci of septic thrombosis of the cavernous sinus are infections about the nares and the upper $11 p$.

Day (13) also believes that it occurs more frequently resulting from nasal or orbital infections than from aural infections.

According to Brown (6), cavernous sinus thrombosis occurs in a small percentage of cases of infections about the nares and $11 p s$.

Turner (43) believes that the incidence of cavernous sinus thrombosis is much greater as seen at autopsy than is suspected during life. He belleves that if the blood spaces of the sinus are only partly obliterated, or if complete obliteration is gradual, the circulation is maintained through the sinus or the collateral vessels, and thus compensation takes place. The classical symptoms are based on 
the more or less complete obstruction of venous return. For this reason, he says that statistics of incldence, if based only on the clinical phenomena, are not altogether reliable.

Turner (58) reported that in 88 cases of facial furuncle handled by Dittrich, or 12 cases in which the boil was situated on the nose, one proved fatal ( 8 per cent). The highest mortality occured when the upper lip was the seat of infection; of 10 cases, 4 died (10 per cent). It is gradually becoming apparent that thrombosis of the cavernous sinus is a much more common occurrence than has been represented in the past by the number of cases reported, according to Campbell (10).

D. Object of this thesis.

It has been my sincere attempt in this thesis to describe the subject of cavernous sinus thrombophlebitis complicating facial infections in such a manner as would be of most interest to a competent physician engaged in the general practice of medicine. I have attempted to lay particular emphasis upon the gravity of infections of the face because of the serious complication of cavernous sinus thrombosis which may rapidly follow. After having made an intensive study and review of the literature on these cases, I have attempted to bring together and organize the main troughts and findings of the various men of authority in 
the hope that it will give a rather complete and yet concise resume of this problem, for a clearer understanding, and for the proper management of facial infections and their complications. Because of extensive controversy on many ideas discussed, I am simply presenting what seem to me to be the soundest arguments and data set up by different men, and I can only leave it to my reader, who may have far more experience than I, to draw his own conclusions from the ideas which are presented.

$-9-$ 


\section{ANATOMY}

The cavernous sinus is a venous channel which lies one on either side of the sella turcica. Its lumen is very irregular due to the presence of many fibrous bands. It is about $2 \mathrm{~cm}$. long and $1 \mathrm{~cm}$. In width, and extends from the sphenoidal fissure to the apex of the petrous portion of the temporal bone. Inside of its inner wall are found the internal carotid artery and the sixth nerve, while in the outer wall there are located the third, fourth and the ophthalmic and mandibular branches of the fifth nerves. A thin plate of bone separates the sphenoid sinus

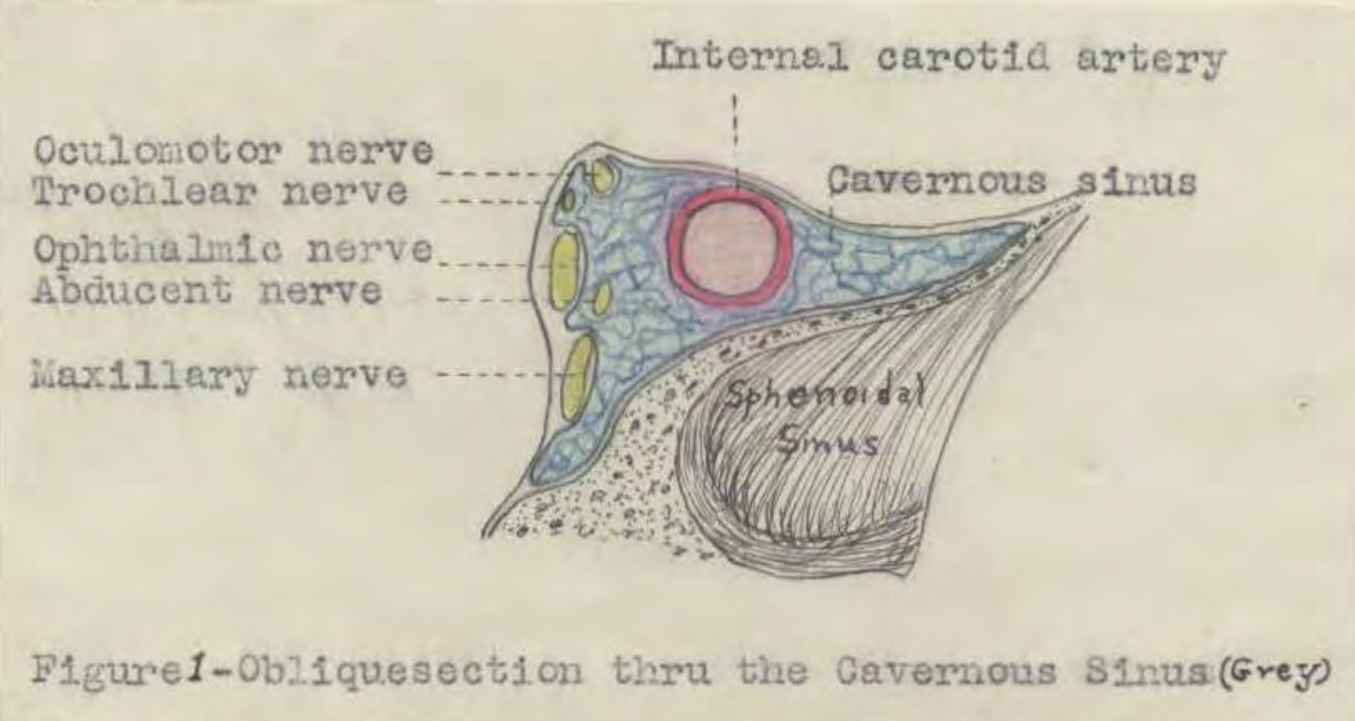

from the cavernous sinus. Directly external to 1t lies the gasserian ganglion. There is a close relation to the optic nerve, and chlasm, and pituitary gland. The cavernous sinus communicates elther directly or indirectly with the veins 
of the face, ear, scalp, orbit, mouth, throat, and nose by means of the connecting or emissary veins. The ophthalmic veins drawin the orbit passing posteriorly into the cavernous sinus. A connecting vein, the nasofrontal vein, forms an important anastomosis between the anterior facial vein and the superior ophthalmic, which makes possible the

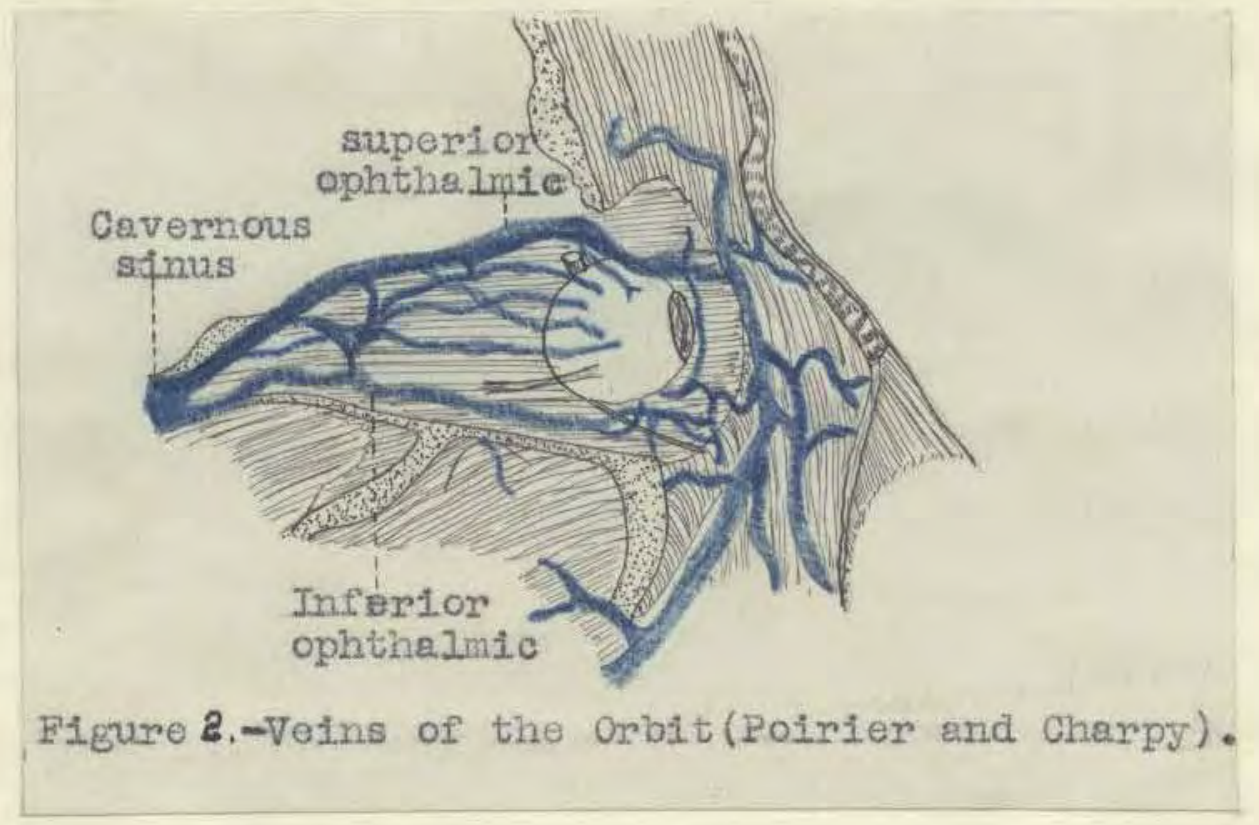

spread of infection from the face to the cavernous sinus. The fact that there are no valves in these veins makes such communications more intimate. Posteriorly the cavernous sinus opens into the superior and inferior petrosal sinuses, the former joining the knee of the lateral sinus, and the latter running into the jugular bulb. A few short veins run from the mucous membrane of the sphenoid air cells into the cavernous sinus. Branches from the ethmoid air sinuses 
drain into the superior ophthalmic veins. The carotid plexus surrounds the internal carotid artery in the crantum, and forms a communication between the anterior portion of the cavernous sinus and the internal jugular vein. The mastold emissary vein communication is formed by the veins of the posterior auricular and occipital regions through the lateral sinus. Also the diplote veins form connections with the veins of the scalp. The cavernous sinuses on both sides comriunicate by means of the circular sinus passing in front of and behind the pituitary gland. The bastlar sinus unites the two inferior petrosal sinuses.

It is therefore seen that there is a circle of vascular channels intimately connecting the peripheral vessels of the face, head, and throat th the large venoug channels of the brain. Normally the blood flows from the orbital and supraorbital veins both down through the angular into the facial vein and also across from the angular into the guperior ophthalmic and on into the cavernous sinus. The blood in the tributaries of the ophthalmic veins draining part of the interior of the nose, the ethmoid, sphenoid and frontal sinuses should flow into the cavernous sinus except the small part that passes down the small branch from the infertor ophthalmic to the pterygoid plexus. Under normal conditions the branches of the factal vein draining the external nose, the lips, and face should flow down the 


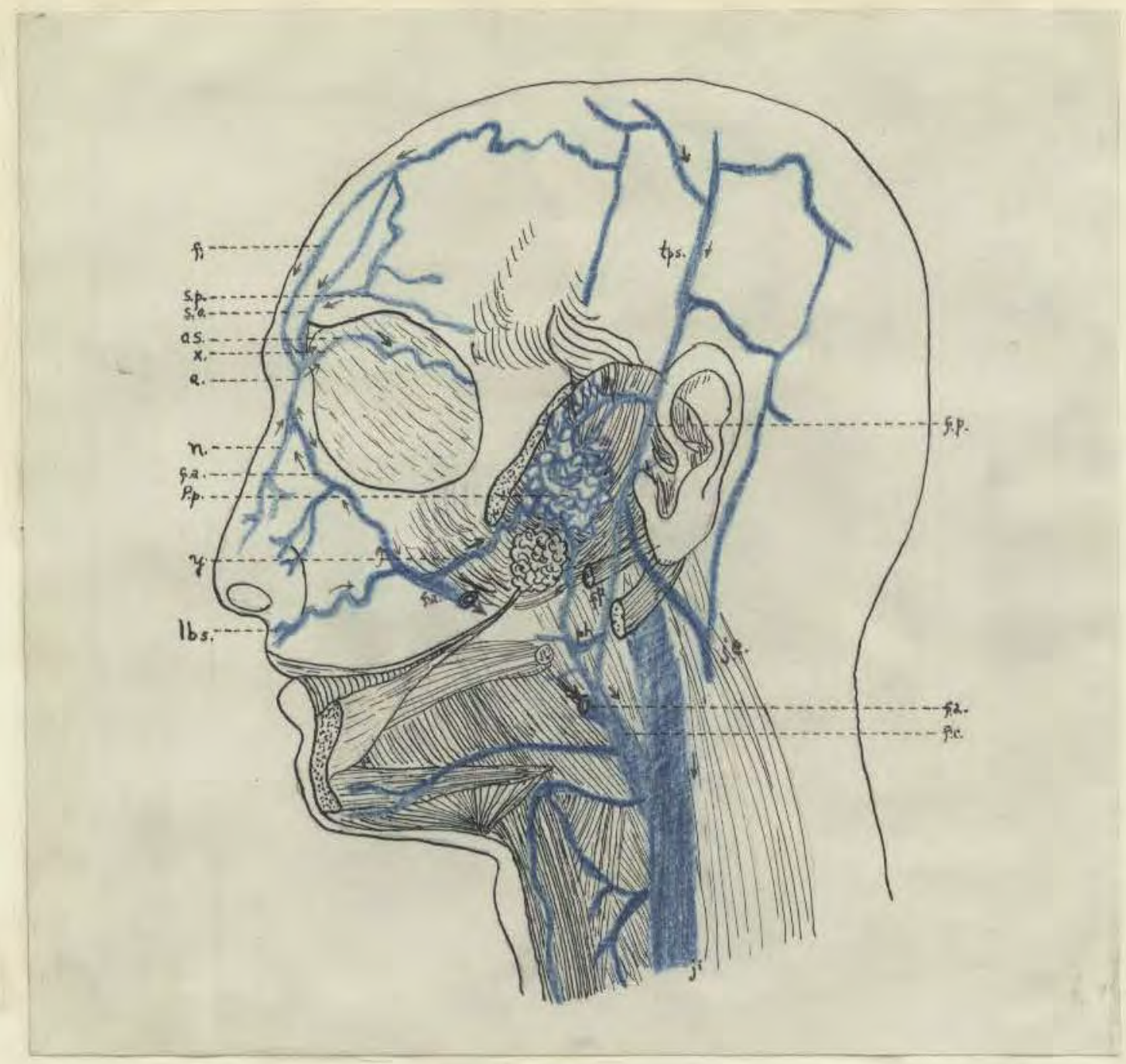

Figure 3. The Internal Jugular and Common Facial Veins and their branches (after Henle).

The zygoma and the left side of the inferior maxilla, together with the masseter, have been removed.

j.i. - Internal Jugular Vein

p.h. - pharyngeal vein

f.c. - common facial vein

f.a. - anterior facial vein

f. - frontal vein

s.p. - superior palprebral vein

g.0.--Superior ophthalmic vein

o. s.- superior ophthalmic vein

$x$ - nasofrontal vein a. - Angular Vein

n. - Nasal vein

P.p. - Pterygoid plexus

lbs. - superior labial vein

f.p. - posterior facial vein

j.e. - external jugular

tp. s. - superficial temporal vein

y - communication between facial vein and pterygoid plexus 
facial vein into the internal jugular at the level of the hyoid bone. An important cominunication of the facial vein is the branch known as the deep facial or anterior internal maxillary vein originating in the pterygoid plexus and opening into the facial vein where that vessel passes through the zygomatic muscles. This pterygoid plexus not only communicates with the facial vein, but also with the pharyngeal plexus, and with the cavernous sinus through the small veins which traverse the foramina ovale, Vesalii, lacerum medium and rotundum, and with the inferior ophthalmic vein through a small branch passing down through the sphenomaxillary fissure. The pterygoid plexus receives blood from the pharyngeal, fanclal and dental regions and should transmit its blood either anteriorly into the facial vein or posteriorly into the external jugular vein via the temporomaxillary vein. The following outline by Meyers (50) is of value in showing the relation of these veins and the areas they drain to the cavernous sinuses:

Thrombosis of the cavernous sinus

From

1. Anterior scalp and face.

2. Orbit

3. Nose
Through

1. Frontal, supraorbital, Facial, Angular and ophthalmic veins. Ophthalmic Veins

1. Ethmoidal veins

2. Sphenopalative vein through pterygoid plexus. 2. Foreman ovale

3. Anterior facial, angular, and sphenoidal veins.
Opening in Skull

1. Sphenoidal fissure.

Sphenoidal fissure

1. Opening in cribiform plate 
The connections of the cavernous sinus are of primary importance in the understanding of the pathology, symptomatology, and treatment of this condition. The cavernous sinus on each side receives blood from the middle cerebral veins, the sphenoparietal sinus, the veins from the sphenoidal air sinus, and from the superior and inferior ophthalmic veins. A comrantcating vein joins the superior ophthalmic to the angular vein, which is often of considerable size. The angular vein is formed by the junction of the supraorbital and frontal veins and is continued down the side of the nose as the anterior facial vein, which 1s joined by many small tribulaties from the subcutaneous venous plexus on the side of the nose. Other connections of the cavernous sinus are mainly efferent channels; though this by no means precludes these channels as routes of spread of thrombosis. The superior and inferior petrosal sinuses pass from the cavernous to the lateral sinus, and emissary veins pass through the base of the skull to join the pterygoid venous plexus, which provides a direct communication between the soft palate, fauces, pharynx and the cavernous sinus.

Campbell (10) calls attention to the absence of valves in the facial, angular, and ophthalmic veins so that there is nothing to prevent the passage of blood in a reverse direction. He states that the direction of flow in these intracranial venous channels is frequently changed because of such 
factors as change of gravity, muscular exertion, relative pressure within and without the craniun, and the respiratory cycle.

Campbell (10) emphasizes the fact that the lumen of the cavernous sinus is filled with a large number of criss-cross trabeculae which are so extensive and interlaced that the flow of blood is very slight and may be easily blocked, which predisposes the sinus to thrombosis.

\section{ETIOLOGY}

Absence of valves of the facial and intracranial veins, including the ophthalmic and veins of the pterygoid plexus, along with the slowness of the circulation and the frequent reversal of circulation is believed by Campbell (10) to be of prime importance in the cause of cavernous sinus thrombosis from facial infections.

Trauma, according to Kartin (41), is an important factor in the etiology of these cases showing sinus involvement. Dixon (15) lists four factors playing an important part in these foci:

1. The early and frequent trauma.

2. The absence of subcutaneous fat on the upper 1ip.

3. The active muscular supply to this region.

4. The inability of the veins that drain this area to collapse. 
According to Turner (58) the face is a region in which the skin comes imnediately under the influence of muscular action. Facial movements being so frequent tend to diffuse the infectious materlal into the surrounding tissues, thereby increasing the area involved. Since the superficial faclal veins are linked up with the intracrantal blood sinuses, the micro-organisms may readily reach these large blood spaces.

There may be cases of thrombosis which occur without an infectious etiology, such as one descrtbed by Belgler (2). According to Campbell (10), in a large rajority of cases the extension to the cavernous sinus is explained as being a retrograde thrombophlebitis, beginning at the primary focus of infection, but he says that this explanation does not satisfactorily explain the rapidity of the symptoms of cavernous sinus involvement seen following the original infection.

Campbell (10) has noted the early appearance, in from one to three days, of symptoms referable to the involvement of the third, fourth, and sixth nerves, and he naturally concludes that the infection in the cavernous sinus is so severe as to extend into the venous wall thus involving the nerves. He feels that the infection can reach the cavernous sinus only by an infected embolus lodging in the intraspinous network from the original focus and not by a retrograde thrombophlebitis. 
There 18 an attempt, Campbell (10) believes, to prevent the infection from reaching the circulation by the formation of a sterile thrombosis of the small veins immediately around the infection. If the infection is controlled very shortly, such a thrombus does not become infected, and does not spread rapidly through the veins. However, if the abscess does not recelve external drainage the thrombus extends ahead of the infection as an attempt on the part of nature to prevent this infected material from getting into the blood circulation. If allowed to go on, Campbell believes that the blood clot is involved, and as it breaks down pus is formed. He believes that the breaking down process with the extension of the infection along the vein occurs slowly, and depends on the virulence of the organism. However, if the infection in the vein overtakes the clot ahead of it, then a chill and high fever develop due to a bacteremia and septicemia. Campbell (10) thinks that the throwing of this infected material as emboli into the circulation explains the sudden onset of cavernous sinus thrombos 1s.

It has been noted by Martin (41) that manipulation of furuncles of the face frequently results in cavernous sinus thrombosis. He explains that if a small puncture is made in furuncles of the face it usually severs or nicks one of the smaller veins. The blood which escapes is only partially external, some of it extending along the lines of least 
resistance within the tissues. The blood within these tissues is stagnant, and makes an ideal culture media for bacteria. Around each focus of infection a wall of leucocytes rapidly forms. According to Martin (41), on the integrity of this wall depends whether or not the microorganisms advance into the tissues. Rough manipulations may, time after time, rupture through the protecting wall. The wall may be repaired, but readily broken through again until finally a dangerous and widespread infection is established.

In searching for some explanation as to why some patients ouffering from furunculosts of the face rapidly develop complications whlle in others the septic process remains localized, I have found no enlightenment. Logan Turner (60) admits that his investigation has thrown no light on this point. He asks, "Is it a question of the virulence of the infecting micro-organism, or of some deficiency in the protective power of the blood against infection?" No satisfactory answer to this question has yet been given to the present date in so far as I can find from the literature. 


\section{SYMPTOLATOLOGY}

Benedict (3) states that cavernous sinus thrombosis is usually first suspected after the lids swell with proptosis, and when signs of septicemia are present. He lists the following symptoms:

1. Bwelling of the lids.

2. Fever.

3. Malaise.

4. Headache.

5. Disturbances of motility of the eye.

6. Proptosis.

7. Visual disturbances (frequently).

8. Engorged retinal vessels may be present after 2 or 3 days.

9. Notor disturbances due to pressure on the third, fourth, and sixth nerves as they pass through the sinus.

10. Choked disc, resulting from obstruction to the flow of the central vein.

11. Symptoms usually bilateral.

Malnzer (39) lists the following symptoms:

1. Headache (early) and inttial chill.

2. High fever from the start, $102^{\circ} \mathrm{F}$ to $106^{\circ} \mathrm{F}$.

a. Fluctuation of the temperature upon softenting of the clot.

b. If complications as meningitis or pyemia occur, the temperature may rise to $108^{\circ} \mathrm{F}$.

3 . One or two chllls dally lasting about 20 minutes. 
4. Nausea and vomiting early, and may be projectile when coma exists.

5. Exophthalmos and swelling of the eyelids in the first 48 hours, becoming more marked later.

6. Choked disks in two-thirds of cases.

7. Vision normal or impaired.

Dean Lewis (38) Iists the following symptoms:

1. Headache.

2. Pain in the eye along the ophthalmic nerve distribution.

3. Unilateral exophthalmos (seen early).

4. Distention of veins of the conjunctiva, eyelids, and supra-orbital region.

5. Edema of the conjunctiva (seen early).

6. Papilloedema (seen early).

7. Loss of vision.

8. Extra-ocular palsies.

Brown (4) calls attention to the fact that signs usually considered pathognomonic of cavernous oinus thrombosis are not necessarily proof positive that such a condition exists, but that they may be due to other cerebral conditions, such as congestion of the cerebral hemisphere. He thus points out that cases of spontaneous cure based on this clinical syndrome may not necessarily be proven cases of cavernous sinus thrombosis.

Bowers (5) reports a case of sinus thrombosis without symptoms . 
Day (14) has described nine cases in which there was a lack of pyemic symptoms. He reports nine such cases out of forty-five, or 20 per cent, and from this he feels the conclusion justificable that a lack of classical symptoms does not necessarily warrant the belief that there is no thrombosis. Furthermore, Day (14) believes that in milder cases the diagnosis is rarely made, and when discovered, nature has already made the cure.

Explanation of the lack of symptoms is made by Turner (59) by the fact that, though infected, the majority of blood spaces are still patent, permitting the continuence of the venous circulation.

Welzenhoffer (61) believes that the symptoms present in these cases of cavernous sinus thrombosis are produced not only by general sepsis, but also by venous obstruction and pressure on adjacent nerves. He believes that the exophthalmos, edema of the lids, and chemosis of the conjunctiva are caused by venous obstruction, while pressure on adjacent nerves is responsible for headache and eye pain due to irritation of the fifth nerve. Furthermore he stated that eye muscle paralysis, and rigidity, and diltation of the pupil result from paralysis of the third, fourth, and sixth nerves, while vision is impaired due to second nerve involvement.

It is of interest to note that cavernous sinus thrombosis rarely remains localized on one side. The infection 
travels through the circular sinus, from which it passes to the vessels on the opposite side, thereby causing double exophthalmos.

The temperature, according to Oppenneim (27) is a less reliable guide in children than in adults, and may be steadily high rather than remittant. 


\section{$\checkmark$ LABORATORY EXAMINATION}

A. Blood findings.

Mainzer (39) gives the following blood picture:

1. Harked leucocytosis in cavernous sinus thrombosis, except when the patient's resistance is low.

2. High leucocyte count with increased polymorphonuclears varying from 85 to 98 per cent, with hemoglobin and red blood cell count decreased. Butler (8) has found that the leucocytosis is usually about 15,000 to 16,000 , of which the polynuclears constitute about 80 to 90 per cent. According to him, an increase of the polynuclears is a danger signal not to be disregarded while an increase in the white cell count may indicate only good resistance, and, conversely, a decrease of the leucocytes maymean an over-whelming of the patient. It is to be remembered that a relatively high polynuclear percentage may mean pus in other parts of the body and that in diseases such as pneumonia, erysipelas, and scarlet fever it may be caused by the disease itself independent of complications.

B. Spinal Fluid Examination.

If a complication of meningitis occurs the spinal fluid is cloudy, and the pressure increased. There 1s usually a leucocytosis with the majority polymorphonuclears, an increase in globulin, and sugar is formed. (39). 
The cerebrospinal fluid, according to Dean Lewis (38), shows an increased cell count and globulin, while in the later stages xanthochromia and organisms may be present in the cerebrospinal fluid. Signs of meningitis may be present, and either subside or progress.

c. Bacteriology.

Welsenhoffer (61) states that the organisms most commonly found are the streptococcus and staphlococcus. The staphlococcus is present usually when the infection ts localized, small, and seemingly unimportant.

A case of cavernous sinus thrombosis believed to be a pure streptothrix infection, with the addition of a few real pus fom ing organisms, is described by Henry Horn (29), but such cases are probably very rare.

Blood cultures may be of value in cases of septicemia (39). 


\section{DIAGNOSIS}

Dorland Smith (55) says that since the only possibility of lessening the extremely high mortality lies in prompt surgical interference, such early decisive diagnosis becomes necessary .

According to schwelnitz (54), an almost certain diagnosis can be made by the following:

1. Cerebral symptoms.

2. Septic temperature.

3. Exophthalmos with lid and face edema.

4. Spread to opposite side within 48 hours (a very important diagnostic symptom in rost cases).

5. Anaesthesia of the cornea.

6. Implication of the motor nerves of the eyes, retinal edema, and distention of retinal veins. Kreutz (33) presents an interesting case of aseptic thrombotic process in the cavernous sinus, and has concluded that the absolute diagnosis in a case even presenting typical symptoms, history, and physical signs of cavernous sinus thrombosis, in the absence of the opportunity to examine the brain stem and cavernous sinus, always remains obscure. Ottenberg (45), (46), in detalled articles explains that ne thinks the determination of the side on which the thrombus exists may be made by comparing the number of bacteria grown from samples from each of the two jugular veins. However, he 
admits that this is still quite an unreliable procedure, and also that the finding of equal numbers of bacteria on the two sides would be of no value in excluding sinus thrombosis.

\section{A. DIFFERENTIAL DIAGNOSIS}

1. From inflammatory process.--The shifting from one eye to the other is a differential symptom between thrombosis and an inflammatory process in the orbital cavity, according to sullivan (57).

2. From sphenoidal sinusitis.--Sphenoidal sinusitis can only be diagnosed by careful examination of the nose assisted by transillumination, radiography, and if in doubt by exploration of the sinuses (7):

3. From orbital cellulitis and tenontis and orbital abscess.--Weizenhoffer (61) calls attention to the fact that in cavernous sinus thrombosis the second eye is almost always affected within 48 hours after the first, which is an important differential sign distinguishing cavernous sinus thrombosis from orbital cellulitis.

Orbital cellulitis may produce swelling of the lids, redness, conjunctival edema, and conjunctivitis as well as such symptoms in cavernous sinus thrombosis, according to Brown (7), but proptosis does not occur until the sinus is involved.

Primary orbital cellulitis is differentiated from cavernous sinus thrombosis by the absence of a great venous stasis, and papilloedema, according to Dean Lewis (38). 
Local diseases within the orbit such as cellulitis, tumor, and tenomitis may, according to Benedict (3), cause similar symptoms. Unilaterality of symptoms aids in diagnosis. He points out that most cases of cavernous sinus thrombosis are bilateral.

Orbital cellulitis and tenonitis often give a history of previous eye trouble, and more signs of inflammation in the eye than is usually seen in a cavernous sinus thrombosis, (II), and the signs of venous obstruction are more marked; also the headache is less severe, and there are no signs or symptoms of meningeal involvement.

Plum (48) describes a case of bilateral orbital abscesses which so closely resembled cavernous sinus thrombosis as to be very disconcerting to all concerned. He also states that occasionally a case of cellulitis may resemble a cavernous sinus thrombosis.

E. R. Lewis (37) states that a differentiation must be made between cavernous sinus trrombosis and --

1. orbital abscess.

2. frontal sinus abscess.

3. periorbital abscess.

4. From erysipelas--Erysipelas may closely

resemble cavernous sinus thrombosis, and the latter may often result from erysipelas acting as a prinary cause of infection. (11). 


\section{PROGRESS}

The story of the development of these cases are all strikingly similar. Martin (41) gives the following typical account. "A small furuncle appears with redness and swelling, usually with one or two days' duration. It is pricked or squeezed. It usually becomes worsẹ. A physician 1s called. He makes a small wound or thrusts a blunt instrument into 1t. The place of puncture is not determined by a visible focus. After each incision the patient grows worse."

The symptoms develop more rapidly if thrombosis begins at the anterior end of the cavernous sinus than when coming from the petrosal end, due to the fact that in the latter case the collateral circulation has more time to establish itself. (61). Death occurs mostly within a week after development of eye symptoms and is due to meningitis. (61).

According to Weizenhoffer (4) the symptoms develop much more rapidly in cases where the thrombosis begins at the anterior end of the cavernous sinus than when it develops from the petrosal end, because in those from the petrosal end there is much more opportunity for the collateral circulation to establish itself. Usually death follows within a week after the eye symptoms have developed and occurs as a result of meningitis ( 61$)$.

In infective cases, according to Dorland Smith (55), the symptoms of obstruction, lic oedema, exophthalmos, and 
chemosis develop early and relatively slowly, reaching their maximum in two to five days, and rarely ten or more, after which they begin to subside. The involvement of the other eye is a relatively late symptom and is more rapid, often - lasting for only a few hours. Symptoms of nerve involvement appear early, and these are soon masked by obstructive Eymptoms. The sepais becomes more marked, and emboli may be present in other parts of the body, particularly in the lungs. Meningeal symptoms and symptoms of an increased intracranial pressure develop frequently, and death may occur in six to forty-eight hours after the second eye is involved. 


\section{PREVENTION; POTENTIAI METHODS OF TREATMENT OF}

FACIAL INFECTIOTS.

Every furuncle of the face and nose should, according to Martin (41), be treated as if it might become a dangerous disease. He believes that rough manipulations and early operations help to spread rather than to limit the infection. ne adrocates rest for the small infection, and that the skin about it be cleansed and covered with some simple ointment. The focus of infection should not be rubbed, pricked, squeezed, or handled. He claims that it is dangerous to try to abort furuncles by puncture through the red or white point with a tooth-pick dipped in phenol, and he warns against the injection of phenol in the indurated tissue. Martin (41) is very hostile toward early puncture before a definite focus of suppuration has occurred, and then tightly packing the small hole to arrest bleeding, as he feels that it creates an ideal medium for bacterial growth, and thence the infection may spread to the labial veins. Local anaesthesta should never be used, according to Martin, as the infiltration further increases the tension, forcing the material deeper into the tissues. He recommends incision with a sharp knife if there is a local abscess or if the part is greatly swollen and livid, or if intolerable pain exists. Free pus is seldom found, but scattered purulent foci, and a hard necrotic core are usually found. Martin states that it is usually necessary to pack tne wound with gauze to check the bleeding, and upon 
the removal later, hemorrhages may occur, and the new granulations may be destroyed. He feels that a large number of simple staphlococcus infections have been changed into widespread and dangerous lesions by ill-advised treatment at the onset of the infection.

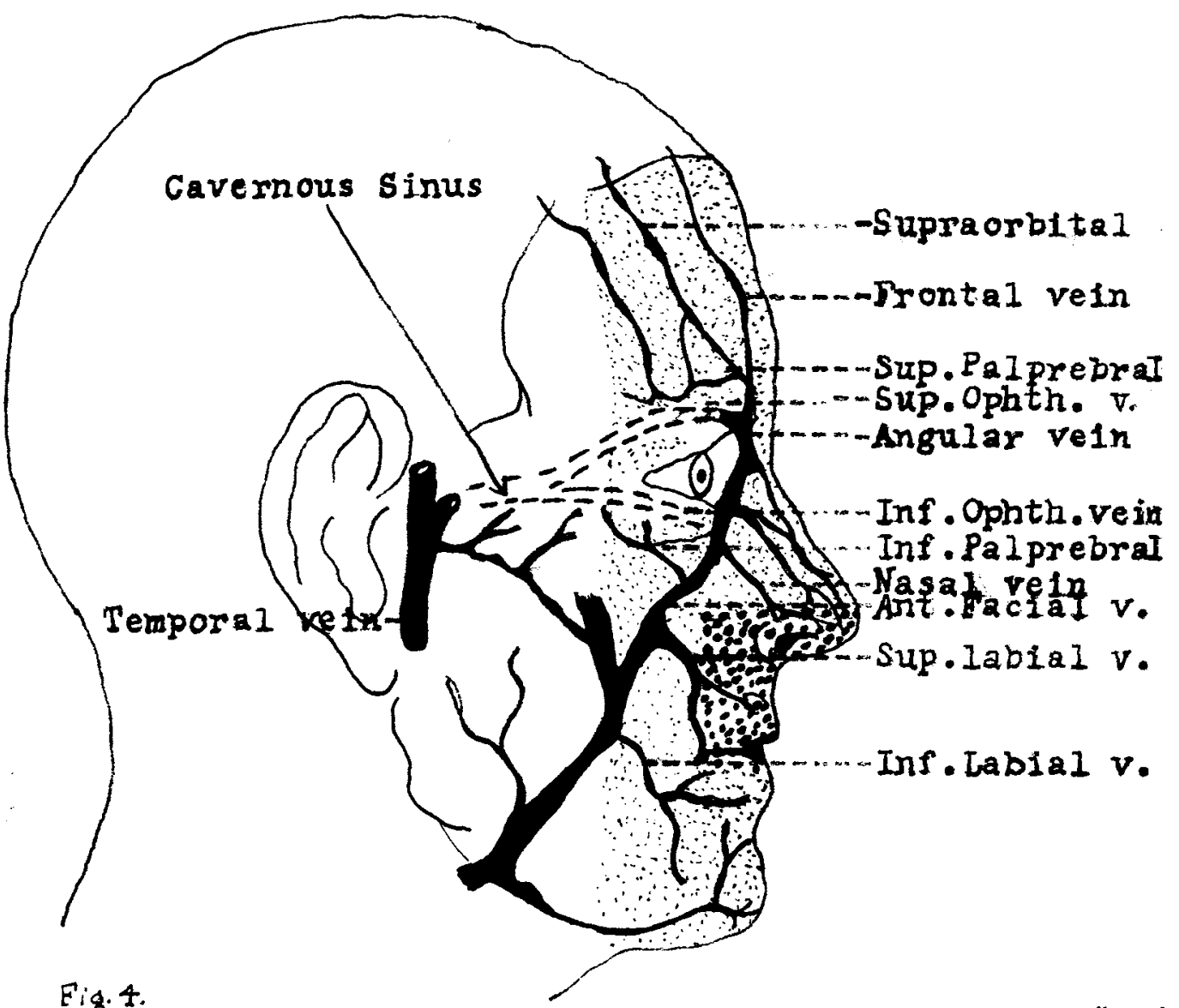

Fig. 4.

DANGER ZONES OF INFECIION ABOUT THL FACE. (HintonlI4: A. Heavy dotted area around the nose and upper $11 p$ is the "critical area" of face infections. B. Iight dots represent danger $z$ one for infections.

Hinton (28) warns against the squeezing of furuncles within the danger zone of the face. (See figure 4). However, 
he admits that numerous furuncles about the face may never lead to serious complications, but that the fatality of the small per cent of cases developing cavernous sinus thrombosis is very great.

Faulkner (23) states that in all of these cases which he has seen, there has been some tinkering with the original focus, either with domestic or professional surgery. He warns against hampering with any facial infections, and against the exertion of pressure to expel the secretion.

Dittrich (58) also found that the mortality was higher in the cases operated upon than in those in which no incision was made.

Weizenhoffer (61) points out the importance of aroiding all mechanical and surgical interference in cases of furunculosis of the face, especially of the nose and upper lip, before localization has taken place.

Thomas (16) in 1932 warns that we must profit by the lessons impressed on us that we should not do meddlesome surgery in furuncles of the face, and that our axiom should be conservatism and watchful watting. Mainzer (39) in 1930 has likewise emphasized this principle.

Mainzer (54) says that he 18 of the opinion that prophylaris is of the greatest importance. Surgery of the face he belleves is bad surgery; therefore in treating primary infections by the use of hot applications and poultices one 
can possibly prevent the spread of the infection. He believes that the scalpel only opens the lymph spaces and dislodges thrombi to be disseminated from the indurated area, and hence should not be used (54).

The rapidity with which an apparently simple local infection can become a severe or even fatal infection has been described as a peculiarity of facial infections. This is graphically brought out by a quotation from one of these writers: "A friend had a pimple in the nose. On Saturday morning he went to a well-known specialist who opened the pimple. On the following Tuesday morning he died." It is hard to believe that so rapid a fatal outcome could have followed if the pimple had been on the face or chest or any part of the body other than the face (13).

Whatever the pathology may be, Day believes that we must accept the fact that a patient with a facial infection is in some danger of deeper and possibly fatal infection. This risk, expressed in percentages of deaths to all cases of facial infection, must be a very small one; far smaller than a surgeon operating chiefly upon ward patients would be likely to realize; but none the less it is a real risk, and should be reckoned with. Day states that it must be adnitted that the spread of the infection depends not only on its situation and extent, but also on the nature of the infective organism, and on the resistant power of the patient (13). 
Day (13) says that the real test of treatment in such cases is not simply that the patient recovers, or the reverse; it is that the recovery begins immediately after treatment is administered, and that the healing is prompt, and with a minimum of scar.

The object of incision, according to Day (13) is to permit the escape of pus and necrotic material. A small incision correctly placed will do this. It must pass through or at least reach the center of infection. When it does this it relieves the abnormal pressure of which the induration is evidence, and thus permits the blood to circulate normally through the tissues, destroying the infective agent and counteracting its injury. Until the physical signs indicate where the center of infection is located, an incision is of doubtful value. It if simply divides edematous tissue, it can have little effect upon the progress of the infection. Surgery of minor infections of the face, especially in the danger zones, is considered as bad practice by Dr. Quincy (51) unless frank pus is very obvious; in such cases he recommends the smallest incision possiole for adequate draining.

Day (13) advocates the use of heat to increase the blood circulation of the infected area, and believes that it may check the infected process, if it is not too severe. This power is clearly a limited one. 
External antiseptics, according to Day (13) may destroy bacteria which are near the surface. He says that many a pimple has been aborted by pure carbolic acid introduced into it on the point of a toothpick. Such measures cannot be expected to control infection which has psssed beneath the skin. The bactericidal power of the Roentgen ray is also very limited according to Day.

Vaccines now available are of some value in the prevention of recurrent attacks of boils, according to Day (13), but he believes that once an acute infection has started that they cannot prevent it. He suggests the use of vaccine therapy along with surgery in the treatment of these cases of facial infections.

The importance of avoiding all mechanical and surgical interference in cases of furunculosis of the face, especially of the nose and upper lip, is likewise emphasized by Weisenhoffer (61). To combat sepsis, and increase resistance he advocates the use of frequent small transfusions and the intraveneous administration of mercurochrome, acriflavine, or similar preparations.

Hinton (28) recommends conservative treatment of all face infections. He advocates the use of heat in the form of flaxseed poultices as preferable to wet dressings. If chemosis is present he recomends the use of hot boric acid compresses to the eyes. Usually the infection localizes with 
conservative treatment and the infection may perforate the skin and mucous membrane as a slough. If the infection falls to localize he recommends the use of a sharp scalpel and general anaesthesia in making an incision without trauma. A rubber drain is then used in preference to the use of gauze. Hot poultices are advised after the incision is made.

Muir (43) recommends the following treatment of infections of the upper 11p:

1. Multiple incisions extending down to the mucous membrane.

2. Injection of 5 per cent carbolic acid solution in the attempt to kill the organism.

3. Application of a hypertonic salt solution with sodium citrate to encourage drainage.

4. The use of antogenous vaccines.

5. Ligation of the facial vein.

Day (13) warns against the mantpulation of any pimples, and states that while squeezing may cause the contents of a pimple to squirt out on the surface it may also press the infection inward rather than outward, thereby causing the rapid spread of infection. The bruising of tissues, he feels, may provide a fine fleld for the growth of infective organisms. Even after lancing a boll it should not be squeezed, and even the slightest pressure is deemed unwise by Day. In order to evacuate the pus and necrotic material he suggests the use of the suction method. In consideration of operative 
measures Day (13) believes we find that the merits of a large incision have been extolled by some surgeons, who have vigorously condemed a small incision. If the incision is correctly placed and large enough to provide an easy exit for the pus and necrotic material he feels that it is better than an even larger incision, and the healing is more rapid with a smaller scar. He has noted that a small incision must be watched and attended to more carefully lest it stick together or dry at the surface, while it should be draining. Avoldance of this difficulty is recommended by the use of hot wet dressings, or by using an ointment.

Crucial and multiple incisions are next in order of severity. They have the advantage of freer drainage or the opening of more than one center of infection, should such exist.

Complete excision of the dangerous furuncle of the 11p, cheek, etc. is suggested by some authorities rather tran incision. H. Heinlein (13) says his elliptical excision should give 100 per cent recovery, and only slight scarring. While there is little doubt but what exclsion may give free drainage, Dr. Foote (13) asks why sacrifice the tissue in no way responsible for the infection, and which if properly cared for will not disturb the body's efforts to overcome the infection.

Probably Brown (7) in 1931 gives one of the best and latest descriptions of the proper treatment of cases of 
facial infection. While recognizing the risk of opening up uninfected tissue and lymoh spaces and dislodging thrombi, he feels on general surgical principles that the pus should be excavated at the earliest time it can be done with safety. Brown (7) gives the following suggestions:

1. For small septic foct of the nose and eye, puncture should be made with a sharpened match stick dipped in liquid carbolic acid.

2. For larger abscesses, hot applications are best used until the first signs of pointing can be seen. Removal of the skin over this area is recommended, and if pus escapes a small pledget of cottonwool soaked in ten per cent cocaine should be lightly packed into the cavity. After a few minutes an orangestick, dipped into liquor hydrargyri nitrate acidus should be gently bored into the core. It is very important to have the wound dry and all bleeding stopped before applying the acid, or the skin may be burned by the overflow of acid. This treatment, though painful, often relieves the local condition without danger of free incision, according to Brown, and may be repeated if necessary.

In the case of a neglected carbuncle of the face, especially on the upper 11p, if there are any warning symptoms of cavernous sinus thrombosis present, Brown (7) recommends 
excision of the carbuncle and advised that it be carbolized, and not incised with undercutting of the flaps as is often practiced to get a good cosmetic result. He says a good plastic operation can restore the lip, but inefficient excision and drainage may lose a life.

\section{B ANGULAR VEIN LIGATION}

Faulkner (23) believes in anterior infectlons that if one becomes suspicious of the complication sufficiently early, ligation of the angular vein might prevent it; but considering the number of infections in this region which never develop any complication it would seem rather radical to tie the vein in all cases. When symptoms have appeared he feels that it is doubtful if ligation of the vein will do any good.

If the eye condition clear up, Horn (39) and Thomas (16) doubt that there was genuine cavernous sinus thrombosis. If there is no initial lesion on the face he states that there may have been a simple venous obstruction. He feels that it is possible to control this by ligation for a time. If, after ligation of the angular vein, the other eye becomes involved, Horn says that we are too late for radical promiseful surgery. This is where the trouble comes in. He feels that with the Eagleton idea, and the Mosher approach to the ginus itself through the sphenoldal flssure that we have made some advance in the mastery of the infection considered fatal in the past. 
According to Day (13) another and more serious operative treatment advocated by many writers is the ligation of the angular, facial or even the intemal jugular vein. He cites that the history of surgery tells of many pecullaf operations which have been popular for a time, and have then been abandoned. He classes such operations as belonging to the age of superstition or at least to an age previous to the clear understanding of correct surgical princlples. What can be more peculiar than the ligation of a single vein to control infection?" he asks. Day believes that the reasoning behind this procedure is as follows: Patients with a fatal infection sometimes die with suppurative thrombosis of the cavernous sinus. The angular facial veing are connected with the cavernous sinus. Therefore ligation of trem will prevent suppurative thrombosis of the cavernous sinus (13).

Day reminds us that infection spreads chiefly by the lymph spaces and lymphatics, and only slightly by the veins. Ligation of a vein predisposes to thrombosis proximal to the point of ligation as is seen in numerous cases of ligation of dilated veins of the leg. The facial veins have so many branches that freely anasthomose with each other and other veins that ligation of one or two trunks must have only a slight effect upon the venous circulation, according to Day. The idea of affecting the flow of blood by the ligation of a single vein seems incredible to Day. 
Day (13) finally believes that, after considering all things, the conclusions seem to be that facial infections are no more peculiar in their treatment than infections of other parts of the body, and that prompt correct incision of a focus of infection offers the best chance to correct the infection locally. He feels that its tendency to spread should be limited, and thus favor a prompt cure of the patient. Day concludes by saying that if one wishes a motto for his guidance in these cases, that he should disregard one that was recently offered, "Noli me tangere", and cnoose rather one with centuries of success to its credit, "Ubi pus, 1 bi evacus." 


\section{PROGNOSIS}

Cavernous sinus infection is fatal in 98 per cent of cases where it is found, according to Quincy (51), and the only chance for cure is early diagnosis with drainage.

In an article by Huir (43) he states that it always puts the patient in a dangerous situation. In general, he has noticed that whenevex a furuncle or carbuncle exists in an area richly supplied with lymphatics, that the patient's life is greatly endangered. He states that a carbuncle on the lip is usualy fatal, and may likewise come in that class because the upper lip is so richly supplied with lymphatics.

of 300 cases reported in the l1terature, 23 or 7 per cent recovered. Eggleton reported 6 recoveries in 32 personal cases, which is 19 per cent.

The literature discloses the fact that a certain number of cases of septic thrombosis cure spontaneously, according to Turner (58).

Turner (58) reports that according to Morean from his 103 cases of facial furuncle, 11 per cent were fatal. In 12 cases the furuncle appeared on the nose; one died ( 8 per cent). In 48 cases in which the boil occurred on the upper 1ip, 7 were fatal (14 per cent). Three other cases were present with a furuncle on the chin, lower 1ip, and cheek. 
Spontaneous recovery may, according to Dear Lewis (38), occur at times, and he reports one wuch case from his own practice which was well 18 years following a bilateral thrombosis of the cavernous sinus. 


\section{$X$ TREA TMENT}

The importance of individualizing the therapy to fit each given case is emphasized by Kopelzky (31). This he believes is especially necessary in cavernous sinus thrombosis. The constitutional reaction of the patient, the extent of the sepsis, the nature of the invading organism, and the specific parthogenesis of the infection, are all of importance in determining the nature and the extent of the operation undertaken (31).

\section{A SURGERY}

It should be the aim of the surgeon, according to Day (13) to make his diagnosis and operate before this infection has gained headway.

Operative measures have few advocates and fewer practitioners according to Dorland Smith (55), although it is probably the most feasible procedure known. Many experienced surgeons feel that the objections to the operation overshadow its advantages, but this fact may be discounted because of unproven measures, according to Smith. Opinion is not unanimous. Smith is in favor of early diagnosis and early operation. He thinks that the cavernous sinus should be drained if possible before the patient becomes too septic. 
Dean Lewis (38) is strongly opposed to surgery of the cavernous sinus, and says that he feels that it is contraindicated. He condemns efforts to evacuate the sinus.

Powell (50), after making a thorough review of the literature has concluded that surgical procedure in which the cavernous sinus is drained is hardly justifiable, especlally since it presents such difficulty of approach, and the multilocular nature of the sinus. However he goes on to state that he believes that in very expert hands and in favorable cases seen early without a complicating meningtis surgery maybe of benefit. Powell feels that once an early diagnosis of septic thrombosis of the cavernous sinus has been made, the obvious duty of the attending physician is to allow the patient to settle his worldly affairs as completely as possible before the onset of coma.

Eagleton (18) claims that most of his cures were surgical while others claim the contrary to be trie case.

In the streptococcal cases with no abscess formation, surgery canbut do harm, according to Faulkner (23).

After two unsuccessful attempts at surgery, Day (13) has abandoned all direct operative attempts to the sinus; and Iimits his efforts to the drainage of the primary foci of infection, trusting to the slender hope that the infection may be so attenuated that spontane ous cure may result. 
Faulkner (23) condemns the "ultra-radical surgical procedures" either through the removal of the orbital contents or through the middle fossa route stating that the anatomical structure of the sinus is such that no septic thrombus could be removed and therefore for this reason first of all no operation could accomplish much, and reasoning finally trere is very little evidence to warrant such a procedure. He feels about the reported cases of recovery where the eye was removed that equally good results could have been obtained by drainage of the orbit with removal of the ethmoids and orbital plate through the Killian incision.

Christophe (20) thinks that Eagleton's operative success is due to the placing of the sinus at rest through carotid ligature. He believes that "it provided a cure in the case of a patient who was apparently doomed."

Kopetzky (32) has laid down certain princlples for the surgical treatment of cavernous sinus infection:

a. When such cases are reasonably susplcioned, the inflamed sinus 1 s placed at rest by fractional or complete ligation of the common carotid.

b. Then the large venous radicle or sinus into which the vein empties or through which the primary or secondary area of infection has been transmitted, should be opened surgically.

c. Repeated transfusions, preferably from an immunized donor should then be made in order to aid nature in its reparative processes. 
Weizenhoffer (61) believes the treatment to be mostly symptomatic but that the focus of infection should be drained where it is possible.

According to Chisolm (11) when operative treatment is contemplated the location of the focus of infection should be used in declding upon the route of aporoach. In 1llustrating, he suggests that if the orbit is the focus, the route of Mosher may be best used, but if it is the etrmolds or sphenoids the route of Langworthy might be used, etc. The same Idea is upheld by Ballance (1), who states that the cause of the infection of the cavernous sinus being determined, the aporopriate operation will be obrious as the infection is one continuous process thich should be followed from its primary site to its ultimate extension. According to Dorland Smith (55), the cholce of routes will be that by which the operator 1s most familiar; or perhaps that by which the infection has entered.

In the intranasal cases with a definite orbital abscess, Faulkner (23) recommends evacuation by the killian route and the ethmoids exenterated.

Goldthwart (25) describes the following routes for direot approach to the cavernous sinus:

1. Mosher route--exenteration of the orbit by the Kroenlein procedure, then resection of a part of the external orbital wall (greater wing of the sphenoid), 
elevation of dura, and direct extension into the cavernous sinus. While anatomically practical, Goldthwart says it is a very mutilating operation, and the risk of accidental damage to other structures is very great.

2. Approach after the fashion of the Gasserian ganglion removal of Hartlew--Krause through the side of the skull has the disadvantage that the operator is working at too great a depth beneath the brain, giving the great danger of damage to other structures, particularly the carotid.

3. Approach via the antrum is suggested by Luc (25), but is very unsatisfactory.

4. Approacn through the sphenoid is advocated by Langworthy, and may be possible in cases where the sphenoid is properly shaped and easily reached, but may be impractical in many cases where it is inexcessible.

Quincy (51) adrocates the transorbital route of Dr. Mosher as the most feasible.

In a very interesting article by Hosher (42) he describes in detall the surgical tec nique and procedures of the orbital approach to the cavernous sinus. He points out that its drawback is the necessary removal of the eye. In the sertous 
cases he feels that when a reasonably sure diagnosis can be made, the eye 18 already useless. He says that the patient without operation is doomed. In answering the question as to whether the eye should be sacrificed, Mosher feels that both scripture and surgical sense call for it.

The approach to the cavernous ginus through the orbit is thought by Mosner to be the direct and natural way. The essential part of the operative procedure is the enlarging of the sphenoidal fissure, and he feels that this is simply the opening wider of the anatomical gateway tinrough which the sinus emerges from the skull.

Invasion of the cavernous frowthe front and "boils" in the facial region in Mainzer's (39) experience means pus in the apex of the orbit.

Hainzer states that he o never seen multiple punctures of the orbit but add to the already existing infective process. He believes that conditions of primary orbital abscess in the light of modern clinical and operative findings are extremely rare. Et moidal and frontal ouppurations with their invasions of the orbit explain many of these cases of orbital abscesses. Mainzer believes that by all means, in genuine cavernous sinus thrombosis, multiple punctures of the orbit destroy all chances of success. Mainzer (39) states that he is familiar with the Kroenlein peration of the temporal region, but believes trat it is too conservative in the presence of 
such a formidable menace as we are considering. Much courage is necessary to advise a complete enucleation when no blindness is yet present. But Mainzer believes that it has only required enlarged experienoe, and a few post-mortems to convince him that there is always more pathology in the apex of the orbit than is suspected. He feels that it is our chief objective to reach the apex of the orbit as quickly as possible before the 1ntracranial invasion. Mainzer says that "exophthalmos is an infallible guide that radical measures must be instituted." Thomas (16) is of like opinion with Mainzer on this idea.

In a very recent article by Thomas (16) he states that the invasion of the cavernous sinus front as by "boils" in tre facial region means pus in the apex of the orbit. He says that he has never seen multiple punctures of the orbit act other tran to increase the already existing infective process. 


\section{B INTERNAL CAROTID LIGATION}

Wells P. Eagleton first expressed the 1dea that the pulsation of the internal carotid which courses within the cavernous sinus structure is a factor in the extension of the infection intracranially. The pounding of the artery contiguous to a thrombosed vein must cause an extension of the infection not only within the affected sinus, but through the circular veins, intercommunicating from sinus to sinus, to the opposite hitherto normal cavernous sinus. Mainzer (39) and Thomas (16) regard this anatomical relationship as of greatest importance. Once the hitherto mormal eye becomes exophthalmic, surgery is too late, according to Eagleton, and the inevitable fatal issue occurs. No hemiplegia followed the ligation of the carotid in Eagleton's case.

Since Eagleton's book (18) was published on cavernous sinus trirombophlebitis in 1926, he has demonstrated that cases favorable to carotid ligation are the subacute and chronic cases. He reasons in a later article written by him in 1929 (20) that in the acute cases, the associated phlebitis of the inferior cerebral veins causes a meningitis, as soon as the infective process enters the cranium because the cerebral veins run free without fibrous sheaths in the fluid of the large lake of the chiasmal cisterna; consqquently infection is rapidly disseminated through the basal cisterna 
and over the cortex by means of the vascular and respiratory impulses.

Langworthy (34) found that 25 per cent of cases in whom the internal or carotid have been ligated die with symptoms of hemiplegia and he emphasizes in 1916 that in the future he would keep away from such procedure of ligation of the carotid.

Thomas (16) likes to use a modifled Mosher treatment. He ligates the internal carotid instead of the common carotid, and he also believes that early enucleation with complete exenteration of the orbit without exposure of the sinus might affect a cure. But he states that he would always ligate tie carotid.

Ligation of the carotid on the affected side to put the part at rest has been tried but its value is not yet proved according to Faulkner (23) (1931).

Dr. Thomas (39) has modifled the Nosher 1dea. He ligates the internal carotid instead of the common carotid, and he also has the idea that if he catches his patient very early, enucleation with complete exenteration of the orbit without exposure of the sinus might effect a cure. But he says he would always ligate the carotid. 


\section{INTERNAL JUGULAR LIGATION}

Quincy (51) advocates the ligation of the internal jugular vein on the same side to arrest the spread of the infection to the general circulation.

sir Charles Ballance (12) gives the following indication for ligation of the internal jugular:

1. In acute pyemia and septicemia.

2. If the sinus wall is gangrenous.

3. If blood in the jugular bulb is proven or suspected to be clotted.

4. If the jugular vein is thrombosed. He believes that the views that the operation on the vein is never required, and the view that operation on the vein is always required, are equally erroneous.

A case of cavernous sinus thrombosis occurring here in Omaha is described by Dr. William Nolan (44). Ligation of the jugular veln was done with the idea of preventing somewhat the dissemination of infectious emboli into the general systemic circulation, and thereby preventing the formation of the metastalic abscess. Thus by slowing the rate of absorption of purulent material, Dr. Nolan felt that the patient's blood stream could then be fortified with enough antigermicidal measures to offset what was there already and what got in through collateral circulation. The case recovered. $D_{I}$. J. F. Langdon performed the operation of the fugular ligation, 
and these two men believe that ligation of the jugular on tre invaded side has more tendency to recovery.

It is of some interest to know that the British think of jugular vein ligation. In an article from the British Medical Journal (2l) it states that the consensus of opinion at Glasgow is that jugular vein ligation should be adopted when the jugular vein is obviously infected, or when infection of the jugular bulb has been diagnosed; and when, after operation, it is found to be impossible to clear out the whole of the infected clot, or, the sinus having been cleared, the symptoms of infections continue.

It is clearly pointed out by Colledge (12) that the object of the operation on the jugular is first, to provide free drainage for any septic material in the sigmoid sinus, bulb, or jugular vein; secondly, to cut off the escape of septic material into the general venous circulation.

Houser (27) reports a very interesting case in which thrombosis of the left sigmoid sinus followed a submucous resection of the nasal septum. Llgation of the left internal jugular.vein was done, and also an operation on the sinus. Following the removal of blood clots, the vessel was packed with a mercurochrome-220 soluble pack. The patient made an uneventful recovery. Houser feels that the internal jugular ligation played a very important part in the recovery, and also that the blood transfusions were of decided value. 
D MEDICAL TREATMENT

According to Weizenhoffer (61) the treatment is mostly symptomatic with drainage of the focus of infection where possible. He states that the use of frequent small blood transfusions, the intraveneous injection of mercurochrome, acriflavine, or similar preparations are recommended. Eagleton claims that most of his cures are surgical, while otners claim the contrary to be true. Early diagnosis and prompt attack of the sinus is believed by most men to be the best-known means of treatment of these cases.

Dean Lewis (38) says that medical treatment is confined to palliation of symptoms.

Mann (40) reports two cases of lateral sinus thrombosis which gave good results following the intraveneous injection of mercurochrome. However I have found very few men who recominend the use of mercurochrome as a means of treatment, in cases of cavernous sinus thrombosis, and it seems that the value of its use is still greatly questioned.

E. R. Lewis (37) is opposed to surgery in these cases, but believes the use of bacteriophage or intraveneous mercurochrome to be worthy of consideration. He believes that the thins of greatest value to the patient are intensive and unremitting devotion to general systemic and supportive and detoxicating measures, in the hopes of attaining the best protective tissue reactions and the greatest protection to local traumatism during the critical period of the process. 
Blood transfusion from immunized donors is recommended by Eagleton (18) p. 168, as worth trying in any case.

Dr. Langworthy (34) in 1916 suggested the use of $X$-rays in clearing up many possible affections of the sinus. However I have found no further mention in the literature advising the use of X-ray for these cases.

In a recent article (56) by Stout in 1931, he explains and advocates the use of bacteriophage in these cases of septic cavernous sinus thrombosis. He believes that the early sterilization of the blood stream prevented the development of metastatic foci in the lungs and elsewnere. He feels that it localized tre infection and confined it to the original sites. Stout states that he has seen many cases of severe cellulitis of the face arising from foci about the mouth or nose in which local or subcutaneous use of bacterloprage caused the cellutitis to subside rapidly with localization, and rellef from pain, and a prompt termintion of the infection. The therapeutic value of antistaphloccic bacter10phage filtrates has been disputed greatly, but stout in his article (56) defends its use very strongly and lists many other nen wikewise uphold its use. Stout says that it is well-known that staphloccic infections of the face, nose or lips are common and all potentlally dangerous. Trese, he feels, can be promptly and certalnly relived by adequate bacteriophage treatment. He says it should, of course, be 
combined with surgery as seems indicated in each case and should be used locally, subcutaneously, and intraveneously in the hopes of saving more of those who are so unfortunate as to have these factal infections complicated by a septic thrombosis of the cavernous sinus.

\section{CONCLUSION}

The general concluding thought left by most of the men of authority on tis subject is that they are hoping that operative technique may soon be developed which wil combat this condition, although they recognize the great need of becoming more acute in the early recognition of thrombosis of the cavernous sinus than they have in the past. This need is clearly brought out by Reese in his recent article (52)

Infection of the cavernous sinus usually appears with such suddenness as to make impossible any active attempt to prevent it. Once established, we are dependent on such therapeutic measures as have been advocated by Eaglet on, Mosher, and others, such as ligation of the carotid and evacuation of the sinus through the petrous pyramid, through the orbit, or through the sphenoid sinus. The great danger

- of cavernous sinus infection is tre complicating meningitis 
(10) which terminates these cases, and until therapeutic measures become more satisfactory for combating septlc meningitis, it is obvious that the extremely high mortality of these cases will continue. 


\section{BIBLIOGRAPHY}

(1) Ballance, Charles A., A Case of septic thrombosis of the left sigmoid, left cavernous, and left inferior petrosal sinuses. Lancet pp. 1001-1005, oct. $12,1912$.

(2) Betgler, S.K., and Baci, K. J., Cavernous sinus thrombosts; an unusual case. J. Am. M. Ass., Chicago, 1 XXXV, po. 111, 1925.

(3) Benedict, V. L., Cranial sinus thrombosis, ophthalmologic aspects, Surg. Gynec. and Obst. 52: 464-470, Feb. (No. 2A) 131; abstr. Proc. Staff Meet., Mayo Cl1n. 5: 367, Dec. 17, 1930.

(4) Beyer, T. E., Syndrome of cavernous sinus thrombosis due to venous congestion of right cerebral nemisphere, Laryngoscope 42: 632-634, Aug. 1932.

(5) Bowers, Wesley C., Sinus thrombosis for nine weeks without symptoms. Laryngoscope, XXXI: 724, 1922.

(6) Brown W. G. S., Thrombosis, cavernous, in infection about the nares and upper lip. J.A.H.A. Vol. 97, Pt. 1: $282 \mathrm{ab}, J u 1 y 25,1931$

(7) Brown W. G. S., Cavernous sinus thrombosis; fatal complication of minor facial sepsis, Lancet 1: 960-962, May $2,1931$.

(8) Butler, Ralph, Infective sinus thrombosis, Penn. M. J. XX: 277, 1916-1917.

(9) Campbell, E. H., Cavernous sinus thrombophlebitis following tonsillectomy; Ann. Otol. Fin. and Laryng. 4l: 170-174, March 1932. 
(10) Campbell, E. H., Anatomical and Clinical Considerations, Ann. Otol. Rhin. and Laryng. 42: 51-63, March 1933.

(11) Chisolm, J. Julian, and Watkins, S. Shelton, Twelve cases of thrombosis of the cavernous sinus; from a study of 50,000 surgical histories in the Johns Hopkins Hospital. Arch. Surg. 1:483-512, 1920.

(12) Colledge, L., Some difficulties presented by cases of septic sinus thrombosis. Brit. Her. Jour., ii: 460 , July 1922 .

(13) Day, Ewing W., Treatment of lateral and cavernous sinus thrombosis, Atlantic Med. Journal, Vol. 27: 560, June 1924 .

(14) Day, Ewing W., Report of Spontaneous cure of 6 cases of unrecognized sinus throrabosis accidently discovered during operation, Laryngoscope, Vol. 25: 757, 1915.

(15) Dixon, 0. Jason, The Pathologic Examination in cavernous sinus thrombosis, as a guide to the diagnoses, prognosis, and treatment. J.A.M.A. LXXXVII: 10881092, oct. 2, 1926.

(16) Dupuy, H., H. F. Bresster and A. Thomas, Left cavernous sinus thrombosis; case, Laryngoscope 42: 931-933, Dec. 1932 .

(17) Dwight, E.W., and Germain, H.H., Thrombosis of the cavernous sinus with report of cases, including one cranial operation. Surg. Jour., 146: 456; May, 1902 . 
(18) Eagleton, Wells Phillips, Cavernous sinus thrombophlebitis and allied septic and traumatic lesions of the basal venous sinuses; a clinical study of blood stream infection, The MacMillian Cornpany, 1926.

(19) Eagleton, W.P., Oarotid venous plexus as path of infection in thrombophlebitis of cavernous sinus; its relation to retropharyngeal and spenoidal suppuration. Arch. Surg. 15: 275-287, Aug. 1927.

(20) Eagleton, W.P., Cavernous sinus thrombophlebitis, Arch. of Otolar. 10:652-653, 1929.

(21) Editorial, The diagnosis and treatment of septic sinus thrombosis, Brit. Med. Jour., il: 479, 1922.

(22) Bmenhiser, J.L., Cavernous sinus thrombosis following submucous resection; case repott, U. States Nov. M. Bull., XXIII: 141-144, 1925.

(23) Faulkner, E.R., Rhinological aspects of cavernous sinus thrombosis, surg. Gynec. and obst. 58: 474-478, Feb. (No. 2A) 1931.

(24) Foote, E.H., Local treatment of infections of the face, Amer. Jour. of Surg., VI: 438, 1929.

(25) Goldthwalt, R.H., Thrombosis of cavernous sinus of otitic origin, N1litary Surgeon, XLIX: 430, 1921.

(26) Grey-Human Anatomy, 18 th edition, p. 651.

(27) Hemmeon, Halifax, A case of cavernous sinus thrombosis of otitic origin by direct infection of petrosal sinuses, Jour. of laryngol and Otol. XXXVII: 281, 1922. 
(28) Hinton, J. W1lliam, The danger of infection about the face. Annals of Surgery 85: 104-106, Jan. 1927.

(29) Horn, Henry, Cavernous sinus thrombosts due to organisms of the streptotnrix group, Ann. Otol. Rhino, and Laryngo1, XXII: 989-1006, 1913.

(30) Houser, Karl M., Submucous resection of nasal septum followed by complications of acute otitis, mastolditis and sinus thrombosis, Arch. Otolaryng. 7: 631-639, June 1928.

(31) Kopelzky, S.J., Acute and chronic otitis media and sinus thrombosis; surnarles of bibliographic material avallable in the field of otolaryngology, Arch. Otolaryng. 15: 575-583, Oct. 1932.

(32) Kopetzky, S.J., Acute and chronic otitis media and sbnus thrombosis; summary of blbliographical material, Arch. Otolaryng. 12: 391-394, sept. 1930.

(33) Kreutz, G. C., Primary aseptic cavernous sinus thrombosis Ann. Otol. Rnin. and Laryng., 39: 987-995, Dec. 1930

(34) Langworthy, Fenry Glover, Pathologic affections of the cavernous sinus, Annals of Otology, Rrinology and Laryngology, XXV, Sept. 1916.

(35) Langowrtiy, H.G., Anatomic relations of the cavernous sinus to other structures with consideration of various pathological processes by which it may be involved, Ann. Oto. Rhino-laryngol., XXV: 554 and 775,1915 . 
(36) Lewis, A.C., Cavernous sinus, J. Tennessee M. A., 24: 9-11, Jan. 1931.

(37) Lewis, E.R., Cavernous sinus thrombosis; recovery, Ann. Otol. R inol. and Laryng: 40:341-347, June 131.

(38) Lewis, Dean, Thrombosis of the cavernous sinus, Practice of Surgery, XII: 438,439 .

(39) Mainzer, F.S., Cavernous sinus thrombosis, Pennsylvania M. J., 34: 38-43, oct. 1930 .

(40) Mann, R.H.T., Hercurochrome in Sinus Thrombosis, J.A.M.A., Vo1. 89, Pt. 1, p. 244, $192 \%$.

(41) Martin, Walton, The fatal outcorne of certain cases of staphloccic infection of the face and lips, Ann. Surg., Vol. LXXVI, No. 1, p. 13, 1922.

(42) Kosher, Harris Peyton, The orbital aporoacn to the cavernous sinus, XXIV; 709: Aug. 1914.

(43) Mutr, Bradburn, Carbuncle of the upper 11p, New Orleans Led. and Surgery Jour., IXX: 314, 1917.

(44) Nolan, William, Thrombosis of cavernous sinus, Nebr. M. J. $12: 68$ and $69,1927$.

(45) Ottenberg, Reuben, Diagnosis of Sinus thrombosis, Arch. Otolaryng. 5:43, Jan. 1927. Laryngoscope 37: 424, June 1927 .

(46) Ottenberg, Reuben, Differential Jugular blood cultures in sinus thrombosis, J.A.M.A. Vol. 90 Pt. 2, p. 1602 to 1604. , May $19,1928$. 
(47) Phillips, J., Thrombosis of the cavernous sinuses, Surg. CIin. N. Am., IV, 915-919, 1924.

(48) Plum, F. A., Bilateral orbital abscess simulating cavernous sinus thrombosis, Northwest Med., 30: 371, Aug. 1931.

(49) Pooley, T.R., Cavernous sinus thrombosis; case report, and surgical study. N. York State J. M., XIV: 3.98-402, 1913.

(50) Powell, L.S., Septic thrombosis of cavernous sinus; 2 cases, Ann. Otol. Rin. and Laryng. 37: 909921, Sept. 1928 .

(51) Quincy, J.E., Bilateral cavernous sinus thrombosis; nasal and eyelid infection. New England J. Med. 198: 491-493, May 31, 1928.

(52) Reese, W.S., Cavernous sinus thrombosis, Atlantic Med. J., XXVII: 19-21, 1923-1934.

(53) Sauer, W.E., Infective thrombosis, J. Missouri M. A., 30:6-9. Jan. 1933 .

(54) Schweinktz, G.E., Thrombosis of the cavernous sinus, Atlantic Med. J., XXVII: 551-555, 1923-1924.

(55) Smith, D., Cavernous sinus thrombosis; with notes of 5 cases. Arch. Ophth., XLVII: 482-496, 1918.

(56) Stout, B.F., Septic Cavernous thrombosis; two cases with recovery of one following bacteriophage J. Lab. \& Clin. Med. 17: 28-39, Oct. 1931.

(57) Sullivan, J.J., Thrombosis of lateral and cavernous sinuses, Penn. Med.J., 33: 373-378, Larch 1930. 
(58) Turner, A. Logan, Cavernous sinus thrombosis, Jour. Laryng. and Otol,, XLII: 181, 1927.

(59) Turner A.I., and Reynolds, F.E., Study of paths of infection to brain, meninges, and venous blood sinuses from neighboring peripheral foci of inflammation; meningo-coccal leptomeningitis, deatr, autopsy; inflam. changes in sphenotdal air sinuses and early cavernous sinus thrombosis (streptococcal) case illustrating double infection, J. Laryng. \& Otol., 43: 34-41, Jan. 1928.

(60) Turner, A. Logan and Reynolds, F. E., Suppuration in the right post-ethmoidal and sphenotdal sinuses; orbital abscess; cavernous sinus trirombosis, 41: $73-76 ; 442-453.1927$.

(61) Weizenhoffer, Adolph., Contralateral cavernous sinus thrombosis following furuncle of external auditory canal; recovery, liew York State J. Med., 32: 139-142, $\mathrm{Feb} .1,1932$. 